\title{
ENCONTRO DE SABERES COMO ESPAÇO DE FRONTEIRA
}

\author{
CARLA LAdeIRA PIMENTEl ÁGUAS ${ }^{1}$
}

\begin{abstract}
RESUMO
Este artigo discute o Projeto Encontro de Saberes, implementado pelo Instituto Nacional de Ciência e Tecnologia de Inclusão no Ensino Superior e na Pesquisa (INCTI) na Universidade de Brasília e em uma rede de universidades parceiras, a partir do conceito de espaço de fronteira. 0 projeto, que prevê diálogos sistemáticos entre conhecimentos acadêmicos e não acadêmicos através da inclusão de mestres(as) dos saberes tradicionais como docentes universitários, é analisado com o propósito de debater os desafios e potencialidades do diálogo interepistêmico, tendo a sala de aula como espaço fronteiriço. Para tanto, recorro a percepções e cenários extraídos da edição de 2015 da disciplina "Artes e Ofícios dos Saberes Tradicionais", através de observação direta e análise documental, explorando o potencial emancipatório do encontro entre culturas e epistemes.
\end{abstract}

\section{PALAVRAS-CHAVE \\ Universidade; Saberes tradicionais; Epistemologia.}

\section{MEETING OF KNOWLEDGE AS A BORDER SPACE}

\begin{abstract}
This article analyzes the Meeting of Knowledge Project, implemented by the INC for Inclusion in Higher Education and Research at the University of Brasilia and at a network of associated universities, based on the concept of border space. The project, which provides systematic dialogues between academic and non-academic knowledge through the inclusion of traditional knowledge teachers as university professors, is analyzed with the purpose of discussing the challenges and the potential of interepistemic dialogue, with the classroom as a border space. For it, I use ideas and scenarios extracted from the 2015 edition of the discipline "Arts and crafts of traditional knowledge", through direct observation and documental analysis, exploring the emancipator potential of the encounter between cultures and epistemologies.
\end{abstract}

\section{KEYWORDS \\ University; Traditional knowledge; Epistemology.}

\section{LA RENCONTRE DES SAVOIRS COMME ESPACE FRONTALIER}

\begin{abstract}
RÉSUMÉ
Cet article analyse le projet de Rencontre de Savoirs, mis en œuvre par l'Institut National des Sciences et Technologies pour l'Inclusion dans l'Enseignement Supérieur et la Recherche (INCTI) de l'Université de Brasilia et dans un réseau d'universités associées, basé sur le concept d'espace frontière. Le projet, qui fournit des dialogues systématiques entre les connaissances académiques et non académiques grâce à l'inclusion d'enseignants des connaissances traditionnelles en tant que professeurs d'université, est analysé dans le but de discuter des défis et du potentiel du dialogue interépistémique, avec la classe comme l'espace frontière. Pour cela, j'utilise des idées et des scénarios extraits de l'édition 2015 de la discipline "Arts et métiers des savoirs traditionnels", à travers l'observation directe et l'analyse documentaire, explorant le potentiel émancipateur de la rencontre entre cultures et épistémismes.
\end{abstract}

\footnotetext{
${ }^{1}$ Pós-doutoranda (PNPD/Capes) pelo Departamento de Política Científica e Tecnológica do Instituto de Geociências da Universidade Estadual de Campinas (DPCT/IG/Unicamp).
} 


\section{MOTS-CLÉS}

Université; Connaissances traditionnelles; Épistémologie.

\section{EL ENCUENTRO DE LOS SABERES COMO ESPACIO FRONTERIZO}

\section{RESÚMEN}

Este artículo analiza el Proyecto Encuentro de Saberes, implementado por el Instituto Nacional de Ciencia y Tecnología para la Inclusión en la Educación Superior y la Investigación (INCTI) en la Universidad de Brasilia y en una red de universidades asociadas, basado en el concepto de espacio fronterizo. El proyecto, que proporciona diálogos sistemáticos entre el conocimiento académico y no académico a través de la inclusión de maestros del conocimiento tradicional como profesores universitarios, se analiza con el propósito de discutir los desafíos y la potencialidad del diálogo interepistémico, tenendo el aula como un espacio fronterizo. Para ello, utilizo ideas y escenarios extraídos de la edición 2015 de la disciplina "Artes y oficios de los saberes tradicionales", a través de la observación directa y el análisis documental, explorando el potencial emancipatorio del encuentro entre culturas y epistemas.

\section{PALABRAS CLAVE}

Universidad; Conocimientos tradicionales; Epistemología. 


\section{CONSIDERAÇÕES INICIAIS}

Este artigo explora o tênue espaço de convergência entre o eu e o outro, no âmbito do projeto Encontro de Saberes, visando refletir sobre os desafios e potencialidades de um diálogo interepistêmico. À luz do conceito de fronteira, proponho-me a analisar alguns cenários da execução da disciplina "Artes e Ofícios dos Saberes Tradicionais", ofertada no segundo semestre de $2015^{2}$. Esta fez parte do projeto, executado desde 2010, tendo sido implementado de maneira pioneira na Universidade de Brasília, pelo Instituto Nacional de Ciência e Tecnologia de Inclusão no Ensino Superior e na Pesquisa (INCTI), que faz parte do Programa de INCTs do Conselho Nacional de Desenvolvimento Científico e Tecnológico (CNPq). Sob coordenação do antropólogo José Jorge de Carvalho, o projeto visa o estabelecimento de diálogos sistemáticos entre conhecimentos acadêmicos e não acadêmicos, através da inclusão de mestres e mestras dos saberes tradicionais na docência universitária.

O projeto Encontro de Saberes percorreu uma longa trajetória de desenvolvimento, tendo como antecedentes o I Seminário Nacional de Políticas Públicas para as Culturas Populares, realizado no Rio de Janeiro em 2005, e o I Encontro Sul-Americano das Culturas Populares e II Seminário Nacional de Políticas Públicas para as Culturas Populares, realizado em Brasília no ano seguinte. Dentre as decorrências deste impulso, que envolveu muitos atores, movimentos e instituições, em 2010 foi oferecida a primeira edição da disciplina "Artes e Ofícios dos Saberes Tradicionais" na Universidade de Brasília, constituindo uma experiência-piloto em que mestres e mestras foram convidados(as) a atuar como docentes, ao lado de professores(as) parceiros(as) que apoiavam os diferentes módulos de atividades. A iniciativa baseou-se na percepção crítica acerca do perfil excludente das universidades brasileiras:

"As universidades brasileiras foram constituídas tendo como modelo as universidades europeias modernas e, para isso, operaram sob o signo de uma dupla negação, científica e cultural. Nesse processo, foram excluídos os saberes científicos e tecnológicos dos nossos povos tradicionais - indígenas, afro-brasileiros e quilombolas - e também as tradições culturais, inclusive populares, dos nossos povos e comunidades, como se o ambiente universitário comportasse apenas as expressões culturais de cunho ocidental" (HARTMANN et al., 2019, p. 10).

O projeto nasceu fundado em alguns princípios teóricos e metodológicos, tais como o pensar-sentir-fazer (INCTI, 2015), ou seja, a busca de uma pedagogia capaz de enlaçar essas três dimensões de maneira integrada, negando-se a circunscrever a produção do conhecimento dentro de uma abstração mental. Outro aspecto singular do projeto é a ideia do mestre ou mestra como irrepresentável - ou seja, como presença viva que não pode ser

\footnotetext{
${ }^{2}$ Este recorte se justifica dada a minha participação direta na execução da disciplina daquele ano, o que ofereceu uma perspectiva de observação privilegiada, que agora subsidia a presente discussão.
} 
substituída - bem como a premissa de complementaridade entre oralidade e escrita. A ênfase na relação sujeito-sujeito e a indissociabilidade entre intervenção e reflexão também foram basilares para a concepção do Encontro de Saberes, dentre outras características.

O piloto implementado na Universidade de Brasília ganhou raízes, dando início a um processo de expansão em 2012 a partir da Pontificia Universidad Javeriana, de Bogotá, na Colômbia. Em 2014, a proposta estendeu-se no Brasil, através da adesão de seis instituições: Universidade Federal de Minas Gerais, Universidade Federal de Juiz de Fora, Universidade Federal do Pará, Universidade Estadual do Ceará, Universidade Federal do Sul da Bahia e Universidade Federal do Cariri (esta última, incorporada através de uma pesquisa de pósdoutorado ${ }^{3}$ ). A partir dali, o projeto foi ganhando outros espaços dentro do Ensino Superior a exemplo da Universidade Federal do Rio Grande do Sul (UFRGS) e Universidade Federal Fluminense (UFF) - configurando atualmente uma ampla rede. Neste artigo, realizo um recorte, ao refletir sobre esta experiência a partir de observações diretas por mim realizadas em 2015, somadas à análise documental.

Observo que a fronteira, enquanto conceito utilizado para se pensar sobre a alteridade dentro deste contexto, guarda grande polissemia. Segundo a acepção que delimito para o desenvolvimento desta discussão, o espaço fronteiriço pode ser entendido como um terceiro lugar - ou seja, um espaço intersticial que não pertence exclusivamente a nenhum dos lados do diálogo, e a partir do qual novas convergências podem ser produzidas.

Enquanto um território fluido de relação entre diferenças, a fronteira afasta-se de concepções monolíticas de cultura e identidade. Estas são, portanto, entendidas como forças que se movimentam e se articulam na arena das relações de poder, como ensina Stuart Hall (1996). Sob este ponto de vista, a identidade não é uma essência, mas uma estratégia a partir da qual os sujeitos se posicionam, dentro de um lugar histórico específico. Vincula-se mais ao futuro do que ao passado, podendo ser entendida, segundo Hall, como uma junção temporária ou articulação:

"Eu uso 'identidade' para me referir a um ponto de encontro, o ponto de sutura entre, por um lado, os discursos e as práticas, [...] e, por outro, os processos que produzem subjetividades, que nos constroem como sujeitos sobre os quais se pode 'falar'. Identidades são, assim, pontos de ligação temporária. [...] Elas são o resultado de uma articulação bem-sucedida ou 'encadeamento' do sujeito no fluxo do discurso" (HALL, 1996, p. 6).

O autor acrescenta que, por estar em constante transformação, a identidade deve estar sujeita a uma historicização radical. Semelhante caminho leva Boaventura Santos a descrever a identidade como múltipla, inacabada - enfim, uma "identificação em curso" (SANTOS, 2002, p. 314). Ao analisar os processos de identificação, Homi Bhabha (1994), por

\footnotetext{
3 Pesquisa realizada pela etnomusicóloga Carmen Coopat, sob supervisão de José Jorge de Carvalho, pelo Departamento de Antropologia da UnB.
} 
sua vez, não os considera como a afirmação de uma identidade predefinida ou o cumprimento de uma propensão: a seu ver, trata-se da produção de uma imagem de identidade e a transformação do sujeito ao assumir esta imagem. A linha que separa o nós e os outros revela, assim, sua plasticidade. "A identidade, pois, não é o oposto da diferença: a identidade depende da diferença", lembra Woodward (2011, p. 40).

A ideia de encontro com o outro não implica na formulação de consensos e nem dispensa o conflito. Pelo contrário, a tensão permanece acesa, sem que se ambicione, por isso, buscar caminhos de homogeneização ou apagamento das distinções. É por isso que, segundo Sousa Ribeiro, este encontro deve ser pautado por uma ética da diferença, que, segundo o autor,

"Implicaria, justamente, a crítica a um conceito sobremaneira gasto e abusado como o conceito de diálogo. Não basta, de facto, usar a palavra, como uma espécie de mágica panaceia universal, o que é decisivo, evidentemente, é a forma como surgem definidos os termos do diálogo. E, como é fácil e frequentemente observável em contextos pós-coloniais, a oferta do diálogo, se não for acompanhada da disponibilidade para pôr em causa os quadros de referência dominantes, acaba por não ser mais do que um exercício de poder - não admira que a parte subalterna ou periférica exprima muitas vezes a recusa dessa oferta, normalmente para grande, mas afinal injustificada surpresa da parte ofertante" (RIBEIRO, 2005, p. 82).

Por isso, a palavra diálogo, tão desgastada pelo uso corrente, exige bem mais do que a abstrata conexão entre um emissor e um receptor, que se situam em polos opostos. Os sujeitos, simultaneamente emissores e receptores, precisam deslocar-se para o entrelugar fronteiriço, despindo-se do conforto das relações de poder já cristalizadas para se lançarem no território instável da interseção entre mundos (ÁGUAS, 2013).

É a partir desta abordagem teórica que pretendo desenvolver algumas reflexões, ancoradas na experiência vivida junto à oferta da disciplina do projeto. Trabalho com a hipótese de que as relações em sala de aula proporcionadas pelo Encontro de Saberes são relações fronteiriças, na medida em que se estabelecem metaforicamente em um "terceiro lugar" que não é nem exclusivamente acadêmico, nem exclusivamente oriundo dos povos indígenas e dos povos e comunidades.

Vinculada a este ponto de partida, está também a ideia de que as dinâmicas estabelecidas dentro deste espaço fronteiriço se caracterizam predominantemente pela horizontalidade, ou seja: segundo as orientações teórico-metodológicas delimitadas pelo projeto, o "encontro" não se resume à convivência com a alteridade, mas a uma real ruptura com as relações hierárquicas predominantes, proporcionando um terreno fértil para processos de tradução intercultural, ainda que as tensões sejam mantidas. Outro desdobramento da hipótese central consiste na ideia de que, enquanto um território de instabilidade e criatividade característico da fronteira, no espaço-tempo do Encontro de Saberes a ancestralidade e o novo entram em uma relação dinâmica e não dicotomizada, à 
semelhança do tempo espiralado da concepção quéchua - onde o passado é aquilo que está adiante.

Para dar corpo a esta proposta, começo pela delimitação do marco teórico, que busca refletir sobre a polissemia da palavra fronteira e explicitar o sentido pretendido para o desenvolvimento da presente discussão. A seguir, parto para uma breve descrição do projeto Encontro de Saberes e para a discussão acerca de alguns cenários fronteiriços vivenciados durante a execução da disciplina "Artes e Ofícios dos Saberes Tradicionais". Tais descrições servem de mote para a reflexão sobre a relevância do conceito de fronteira para se pensar no espaço de encontro proporcionado pelo projeto e, de maneira mais abrangente, para a construção de diálogos efetivamente interculturais e interepistêmicos dentro do ensino formal.

\section{O CONCEITO DE FRONTEIRA E SUA POLISSEMIA}

O conceito de fronteira povoa os imaginários, uma vez que seu traçado é carregado de fenômenos: conforme sinalizado por Newman (2006), pode configurar como um desenho - um risco no mapa ou, por exemplo, o muro que divide o México dos Estados Unidos - ou pode ser um processo. Pode ser usado para explicar o que separa os grupos sociais, mas também o que os une. É possível recorrer ao termo para tratar da divisão entre nações, da globalização, das identidades e de muitos outros temas, a partir de diferentes ângulos, muitos deles contraditórios entre si. Recorro aqui a algumas discussões que já desenvolvi em outros lugares (ÁGUAS, 2013; 2017) para abordar brevemente o conceito de fronteira e sua produtividade teórica para pensarmos sobre as possibilidades de desestabilização de hierarquias epistêmicas cristalizadas no âmbito do projeto Encontro de Saberes.

Segundo Walter (2006), como linhas divisórias de diferenciação espacial, temporal e cultural, as fronteiras distanciam a identidade interna da alteridade externa. Mas, como entre-espaços compartilhados, ligam-nas. Portanto, quando falamos de fronteira, estamos perante um significante cuja flutuação é, segundo Sousa Ribeiro (2001), uma fonte de ambiguidades que exige um esforço redobrado de contextualização. O mesmo autor nos informa que o seu sentido literal provém de limes, a muralha imperial, destinada a manter de fora os bárbaros, mas o aparecimento do termo ocorreu já no século XIII, a partir da palavra front - o limite temporário que separa dois exércitos em uma batalha. Na modernidade, o conceito foi associado à noção de soberania, acompanhando a concepção de apropriação do espaço do Estado-Nação (ÁGUAS, 2013).

Novas interpretações de fronteira surgiram a partir da Antropologia. Na esteira de Leach, Hannerz (1997) problematiza, por exemplo, a noção convencional de fronteiras políticas, ao descrever as dinâmicas de interpenetração das culturas. Perspectivas como esta 
passaram a centrar a análise em torno das microfronteiras estabelecidas nos interstícios das sociedades. Desta forma, se a fronteira é entendida como barreira, pode igualmente significar interface. Segundo Albaret-Schulz et al. (2004), um aspecto perpassa todas as suas possíveis acepções: trata-se de um atributo de poder. Diante do seu amplo leque semântico, propus-me a agrupar os múltiplos sentidos de fronteira em três modelos de análise, entendidos como a fronteira que separa, a fronteira como frente e fronteira que une:

\begin{abstract}
"A primeira aceção está vinculada a uma razão relacional e se refere ao que separa os grupos - tenha esta fronteira a forma concreta de um muro ou a subtileza das diferenças identitárias. A segunda está relacionada com o limite em expansão e implica, portanto, no avanço unilateral de um agente transformador sobre determinado espaço. Já a terceira expressa a fluidez dos processos sociais cosmopolitas: no entre-lugar, a justaposição de diversas influências permite a emergência de novas configurações de identidade. A pertença simultânea a mais de um universo cognitivo contradiz a ideia monolítica de cultura - que é então concebida em constante transformação" (ÁGUAS, 2013, p. 9).
\end{abstract}

Ilustrando brevemente estas acepções, a fronteira que separa pode ganhar corpo através de um muro que divide dois quintais ou através das barreiras (militares, burocráticas, alfandegárias, culturais, linguísticas etc.) que separam dois países. Já a segunda acepção, sempre associada a um movimento de expansão contínuo, pode ser ilustrada através da expansão da fronteira agrícola ou da fronteira do conhecimento, traçando um movimento linear rumo a um suposto território desconhecido, com o propósito de conquistá-lo. Aqui nos debruçaremos, porém, sobre a terceira acepção - a fronteira que une - interpretada como um lugar de encontro e negociação. Esta pode surgir e desaparecer, mudar de forma, e tem na fluidez uma das suas principais características. Nesse sentido, o aquém da fronteira é um espaço ocupado, bem como o além da fronteira. E é na fronteira que esses mundos se encontram. "Afinal, a ponte que separa duas comunidades é a mesma que viabiliza a travessia" (ÁGUAS, 2013, p. 3).

Segundo Shields, "Fronteiras são normativamente definidas para serem atravessadas, não para serem percorridas. Se elas são seguidas, o seu status é alterado, transformando-se em virtuais, intersticiais ou liminares espaços de 'interação'" (Shields, 2006, p. 229). Este terceiro modelo de análise não se situa, portanto, de um lado ou do outro - e é por romper com a binaridade que, segundo Sousa Ribeiro (2001), este encontro entre diferenças é transgressor. Portanto, esta metáfora convida ao deslocamento do foco, que é retirado dos núcleos estruturantes para se concentrar nos fenômenos marginais que ocorrem nos instáveis espaços intersticiais (ÁGUAS, 2013).

Em sua discussão sobre o conceito de ambivalência, Bhabha (1994) fala sobre o encontro com a diferença a partir da simultaneidade entre diferenciação e incorporação. Esta abordagem busca desconstruir a visão de relações binárias entre totalidades, para lançar seu foco nos fenômenos que ocorrem entre um lado e o outro - in-between. Sousa Ribeiro (2001) lembra que os border studies, embora retendo a conotação de precariedade e mesmo 
arbitrariedade das distinções fronteiriças, concebem a fronteira como uma zona de encontro e como um espaço que transgride, interliga e reconfigura, sendo que o seu aspecto mais interessante encontra-se na justaposição de diferentes influências. Segundo Boaventura Santos (2002), este é um território movediço que impossibilita o estabelecimento de um cânone único.

Conforme discutido em outras ocasiões (ÁGUAS, 2013; 2017), o espaço de fronteira não é sinônimo de consenso. Tensões e conflitos estão acesos, e é a partir deles que se estabelece o diálogo. As articulações possíveis se dão na efemeridade do espaço-tempo, exigindo de ambas as partes em diálogo um constante exercício de negociação (SANTOS, 2002; MARTINS, 2001). Portanto, o encontro entre diferenças envolve certa dose de esforço, ou mesmo de desconforto, se quisermos. Mas, para Boaventura Santos (2002), é a partir dali que algo realmente novo é capaz de surgir.

O espaço de fronteira encontra complementariedade com outros conceitos, a exemplo da tradução intercultural. Segundo Sousa Ribeiro, esta é uma metáfora central da nossa contemporaneidade, abrangendo toda situação em que se busca a produção de sentido a partir de um relacionamento com a diferença. Nessa acepção ampla, o conceito de tradução revela como não apenas línguas diferentes, mas também diferentes culturas, contextos e práticas políticas e sociais podem ser postos em contato, "de forma a que se tornem mutuamente inteligíveis, sem que com isso tenha que se sacrificar a diferença em nome de um princípio de assimilação" (RIBEIRO, 2005, p. 79). Vale observar que a tradução intercultural não pretende ser plena, arrebatando todos os espaços e dissolvendo as diferenças. Pelo contrário: os processos translatórios favorecem o entendimento mútuo em um contexto de diálogo entre diferentes, mas sempre haverá espaço para os silêncios e para a incomensurabilidade.

Outro conceito que encontra afinidades com a fronteira enquanto "terceiro lugar" é o de interser, de Thich Nhat Hanh. Desconstruindo os binarismos, esta proposta enfoca as relações e as conexões entre tudo o que existe. Segundo o autor,

\footnotetext{
"Se você for poeta, verá nitidamente uma nuvem passeando nesta folha de papel. Sem a nuvem, não há chuva. Sem a chuva, as árvores não crescem. Sem as árvores, não se pode produzir papel. A nuvem é essencial para a existência do papel. Se a nuvem não está aqui, a folha de papel também não está. Portanto, podemos dizer que a nuvem e o papel "intersão"” (HANH apud DEMAMANN, 2006, p. iii).
}

Ou seja, nada existe em absoluto de maneira essencialista, mas tudo está em relação, conectando-se com uma cadeia de interdependências que funciona nos interstícios. Penso que conceitos como o de fronteira, tradução intercultural e interser encontram afinidades com o marco teórico e metodológico delimitado pelo Encontro de Saberes, uma vez que o projeto sublinha as possibilidades de diálogo intersepistêmico, pautado pela 
horizontalidade e pela construção de protocolos de interação entre diferentes fontes de conhecimento:

\begin{abstract}
"A complexidade dos saberes, tal como é entendida neste projeto, exige uma abertura a todos os tipos de conhecimento criados e vigentes no lugar onde está a universidade. Procura uma postura jamais fechada, limitante ou exclusiva, mas sim inclusiva, expansiva, aberta, não sectária, acolhedora. Mas esta abertura não deve ser confundida com uma necessária coesão ou fusão. Por um lado, o projeto promove uma atitude de abertura capaz de acolher as diferenças em um espaço de diálogo que, às vezes, implica em uma incomensurabilidade axiológica e ideológica entre as diferenças. Isso é, a impossibilidade de medir, de apreender em sua totalidade as lógicas que regem os saberes ancestrais e, portanto, suas diferenças com relação aos conhecimentos eurocêntricos. Esta qualidade traz o difícil desafio de aproximar-se daqueles saberes, havendo renunciado da certeza, havendo concedido ao incerto um estatuto no processo pedagógico" (CARVALHO; FLÓREZ, 2014, p. 141). ${ }^{4}$
\end{abstract}

Como explicam os autores, a atitude de abertura proposta pelo projeto reconhece que os saberes são às vezes irredutíveis, o que significa que os conhecimentos tradicionais nem sempre têm um equivalente exato na academia; suas lógicas não podem ser traduzidas linearmente para as lógicas modernas eurocêntricas, nem podem ser reduzidas a uma de suas disciplinas: "O importante é não tomar a priori essa possibilidade de equivalência, de paralelismo entre ambos os tipos de saberes; nem tampouco partir da suposição inversa, de que não há possibilidade de diálogo científico" (CARVALHO; FLÓREZ, 2014, p. 142).

Carvalho e Flórez (2014) também consideram que reconhecer a incomensurabilidade e irredutibilidade é crucial para evitar que a aposta na descolonização dos conhecimentos universitários se mantenha como a substituição dos conhecimentos modernos pelos saberes ancestrais ou a mera tradução - aqui, em um sentido estrito - dos saberes ancestrais aos termos dos conhecimentos ocidentais modernos. Pelo contrário, a abertura proposta pelo Encontro de Saberes exige que as instituições ampliem a diversidade de conhecimentos que poderiam nutrir os programas curriculares, incluindo os modernos. É nesse sentido que, segundo me parece, existe uma forte convergência entre as inovações teórico-metodológicas do Encontro de Saberes e as teorias de fronteira.

\title{
ENCONTRO DE SABERES COMO ESPAÇO FRONTEIRIÇO: DISCUTINDO ALGUNS CENÁRIOS
}

Dentro dos limites da presente discussão, alinhavo alguns aspectos de aproximação entre os border studies e o projeto Encontro de Saberes, que vão desde suas linhas-mestras mais abrangentes até cenários aproximados, microscópicos, de interlocução entre mestres(as) e estudantes. Em 2015, a disciplina "Artes e Ofícios dos Saberes Tradicionais" da UnB foi oferecida pelo Instituto de Artes, tendo sido composta por cinco módulos: Performances da Cultura Popular (trazendo uma discussão introdutória por parte dos docentes, acrescida de uma participação pontual do Grupo de Cacuriá Filha Herdeira),

\footnotetext{
${ }^{4}$ Tradução livre de minha autoria.
} 
Bumba-meu-Boi do Seu Teodoro (DF), Folia do Divino e Catira de Luziânia (GO), módulo de Samba e, por fim, o módulo de Carimbó encabeçado pelo Grupo Sancari, de Belém (PA).

Obviamente, a própria concepção da proposta é favorável ao diálogo: os(as) mestres e mestras dos saberes tradicionais são colocados no papel de docentes universitários, contando para tanto com o amparo de professores(as) parceiros(as) acadêmicos(as). Porém, como já foi amplamente discutido por teóricos que analisam os encontros multiculturais em diferentes contextos, a convivência entre diferentes, por si só, não garante o diálogo. Uma cidade tida como cosmopolita, por exemplo, pode ser na verdade altamente provinciana se os grupos sociais permanecerem em seus redutos. Como sinalizou Boaventura Santos, para culturas dotadas de fortes centros, as fronteiras são pouco visíveis, "e isso é a causa última do seu provincianismo" (SANTOS, 1993, p. 49).

Porém, ainda que não seja uma garantia, a concepção do Encontro de Saberes busca criar um ambiente propício às traduções interculturais entre mestres(as) e professores(as) parceiros(as). Isso porque a sua proposta pedagógica não prevê um protocolo geral, mas sim o desenvolvimento de protocolos de diálogo parciais à medida que se caminha. Tais protocolos, que emergem de maneira contextual para cada experiência de relação mestreparceiro, vai variar de acordo com a área do conhecimento - considerando que serão potencialmente mais fluidos para algumas áreas, como as Artes, podendo ser mais difíceis para outras. Tudo se dá, portanto, dentro da especificidade de determinado encontro, o que exige grande sensibilidade de ambos os lados.

Um desafio a se destacar acerca do trabalho dos(as) professores(as) parceiros(as) é a necessária ruptura com os processos de folclorização que comumente povoam os imaginários, quando a cultura moderna ocidental se vê diante da alteridade. "O índio também ri, o índio também chora, o índio também apronta", mencionou, certa vez, o mestre Álvaro Tukano em uma de suas aulas, buscando desconstruir a imagem idealizada dos povos originários. ${ }^{5}$ Considerando que "a repulsão etnocentrista e a exaltação folclorista são cara e coroa de uma só moeda" (SILVA, 1994, p. 117), o(a) docente deve estar empenhado(a) em aceitar e estimular a horizontalidade do diálogo.

Рara ilustrar brevemente alguns dos aspectos fronteiriços e translatórios da disciplina "Artes e Ofícios dos Saberes Tradicionais", oferecida em 2015 pelo INCTI e pelo Instituto de Artes da Universidade de Brasília, vamos trazer à tona alguns cenários. O primeiro deles ganha materialidade através de uma roda de conversa realizada no jardim externo do Departamento de Música, quando a turma teve seu contato introdutório com os componentes da Folia do Divino de Nossa Senhora da Abadia de Luziânia (GO).

\footnotetext{
${ }^{5}$ Refiro-me aqui ao registro em vídeo de uma aula do mestre em 2010, por mim acessada em 2015.
} 
O mestre Johny Meirelles e seu grupo descreviam para os estudantes os Giros de Folia, as longas cavalgadas empreendidas pelos foliões em homenagem à santa de devoção, que percorre grandes distâncias no decorrer dos dias. Ao cair da noite, os foliões chegam à casa de um anfitrião devoto, com grande festa, cantorias, danças, rezas e fartura de alimentos, nos chamados Pousos de Folia.

Em certo momento dessa primeira conversa, um estudante perguntou se algum Pouso de Folia já havia ocorrido em Brasília, sua cidade natal. Como resposta - e com indisfarçável surpresa - ele ouviu do mestre que sim, muitos pousos ocorriam ali, mobilizando, às vezes, centenas de pessoas. Considerando que a maioria da turma era também nascida na capital federal, os alunos e alunas manifestaram sua admiração: como eles(as) nunca ouviram sequer falar em uma festa que mobilizava tanta gente no seu próprio lugar?

Dali se seguiu uma animada discussão sobre o tema, configurando um encontro entre mundos que dificilmente se interceptariam, apesar de tantas vezes partilharem o mesmo espaço. Perante o completo espanto - que poderíamos denominar como um "desconforto" típico dos espaços fronteiriços - os jovens passaram a conhecer mais a respeito da cultura do seu próprio lugar. É possível dizer que aquele foi um momento de ruptura de visões cristalizadas (a imagem do que é ser de Brasília) através da percepção de rituais até então invisibilizados, gerando o contato dos(as) estudantes com outras culturas sobrepostas sobre uma geografia em comum.

Outro exemplo de encontro entre mundos deu-se durante uma aula sobre o ritmo Tambor-de-crioula, ministrada pelo mestre Gilvan do Vale, membro do Boi do Seu Teodoro. Depois de apresentar à turma os instrumentos (suas características e processos de afinação) e os principais elementos da música e da dança, ele convidou os(as) alunos(as) a não apenas memorizarem e repetirem, mas também a criarem suas próprias canções. Este momento, conforme é descrito pelo diário de bordo de uma estudante, nos oferece vários elementos para reflexão:

"No final, quando já tínhamos parado de dançar, Gilvan desafiou um dos alunos que estava tocando tambor a fazer uma toada. O menino foi cantando e improvisando de um jeito muito próximo ao rap, mas que acabou ficando muito bom. Isso me fez pensar em algo que a Tamá6 falou em algum momento, que na casa do seu Teodoro tinha várias festas, apesar de a principal ser o Boi, como uma escola de samba no carnaval. Fiquei pensando se eu tinha uma noção dessas manifestações culturais como algo tão separado e se na verdade as coisas não eram tão separadas assim ${ }^{7 " .}$

\footnotetext{
${ }^{6}$ Tamatatíua Freire, mestra do Boi.

${ }^{7}$ Depoimento da aluna A.S.P., colhido do seu "Diário de Bordo", elaborado durante sua participação na disciplina "Artes e Ofícios dos Saberes Tradicionais" da Universidade de Brasília, no segundo semestre de 2015.
} 
Se pensarmos neste episódio a partir das teorias de fronteira, temos a materialização de um encontro intercultural através da música. Por seu lado, o mestre Gilvan apresentou o ritmo do Tambor-de-crioula, até então desconhecido pela turma. Em seguida, convidou os jovens a criarem suas próprias toadas, e o resultado dessa aproximação, por parte de um dos alunos, foi uma criação próxima ao rap - que era o conteúdo que ele trazia de seu próprio universo cultural, em seu esforço para abraçar o desafio. Obviamente, o mestre também empreendeu seu esforço, acompanhando com o seu instrumento musical a canção criada, e o resultado "acabou ficando muito bom". Nem rap e nem Tambor-de-crioula, a música emergiu como fruto de uma negociação tão espontânea quanto efêmera - uma experiência única de aproximação entre bagagens culturais, que pode ser configurada como um processo translatório dentro de um ambiente intercultural.

Outro aspecto a se destacar, convergente com o cenário anteriormente descrito no contexto dos mestres de Folia, foi o espanto perante a invisibilidade de outras culturas que compartilhavam um mesmo espaço. "A Tamá falou em algum momento que na casa do seu Teodoro tinha várias festas, apesar de a principal ser o Boi, como uma escola de samba no carnaval", observou a aluna; e a descoberta de algo simultaneamente tão próximo e tão distante a ajudou a perceber que, afinal, as relações com as alteridades poderiam não ser "tão separadas assim".

\section{CONSIDERAÇÕES FINAIS: ENTRE SABERES E FRONTEIRAS}

Delimitamos aqui um recorte acerca do Encontro de Saberes, buscando possíveis afinidades com o conceito de espaço de fronteira, entendido como lugar intersticial de diálogo com a alteridade. Nesta análise, foram pinçados alguns aspectos que corroboram a produtividade teórica do conceito, quando aplicado ao projeto. Pensando nas potencialidades, mas também nos desafios do encontro intercultural e interepistêmico, sublinho a importância da presença do corpo como uma dimensão integrada ao conhecimento, ou seja: ao contrário do modelo científico e educativo convencional, que há séculos o deixou de fora do processo de aprendizagem em nome da racionalidade instrumental e sua cruzada em nome de supostas verdades não contaminadas, as experimentações propostas pelos(as) mestres e viabilizadas através do Encontro de Saberes são atravessadas pela corporeidade e pelos afetos - inclusive no sentido spinoziano.

Conforme aponta um dos princípios basilares do projeto, "a transmissão de conteúdos dá-se a partir da postura de pensar-sentir-fazer. Isso significa que o processo de ensino-aprendizagem não privilegia apenas o campo intelectual, convocando o corpo e os sentidos para participarem no trabalho formativo" (INCTI, 2015, p. 8). Penso que sem essa possibilidade, não seria fácil estabelecer um diálogo real entre ethos e modelos epistêmicos, 
constituindo, portanto, um não-diálogo. Ou seja, sem o corpo e suas sensações, sem o ser e seus sentimentos, não se constituiria um espaço de fronteira.

Gostaria de sublinhar também a dimensão emancipatória de experimentações como essa, em um sentido político. A discussão e a vivência fronteiriça da alteridade é especialmente relevante em um contexto como o que vivemos atualmente: tanto tempo depois da invasão colonial sobre os espaços indígenas, dos horrores da escravidão e do velho sonho de embranquecimento do Brasil, a ideia de cor parece cristalizada ou mesmo reforçada pelas forças conservadoras que continuam povoando os imaginários. Regada pela mídia e amparada, inclusive, por boa parte da intelectualidade do país, a intolerância sobre populações negras e indígenas continua, em um crescer, escandalizando o pensamento hegemônico meritocrático. Como descreve o intelectual quilombola Antônio Bispo dos Santos, o Nego Bispo:

"No plano individual, as pessoas afro-pindorâmicas foram e continuam sendo taxadas como inferiores, religiosamente tidas como sem almas, intelectualmente tidas como menos capazes, esteticamente tidas como feias, sexualmente tidas como objeto de prazer, socialmente tidas como sem costumes e culturalmente tidas como selvagens. Se a identidade coletiva se constitui em diálogo com as identidades individuais e respectivamente pelos seus valores, não é preciso muita genialidade para compreender como as identidades coletivas desses povos foram historicamente atacadas" (SANTOS, 2015, p. 37-38).

Se ao(à) estudante é vetado o direito à universidade, o que se dirá acerca da possibilidade de um lugar de protagonismo para docentes indígenas, quilombolas e de outras comunidades invisibilizadas, expulsas e descartadas pelos avanços colonial e capitalista? Este é um debate intrínseco ao Encontro de Saberes, uma vez que o projeto gira em torno do fluxo de uma correnteza secular, colocando os sábios das civilizações nãoocidentais no lugar de docência. Enquanto espaço de fronteira, contribui - ainda que com todas as lacunas e desafios - com a ruptura dos muros universitários. Segundo creio, a abertura de novos espaços de interseção fronteiriça entre a universidade moderna ocidental e outros paradigmas é não apenas importante, mas também estratégica dentro de nosso contexto latino-americano e, especialmente, brasileiro:

"Dentre os desafios para uma real reestruturação dos conhecimentos acadêmicos do nosso continente - um espaço caracterizado por tamanha diversidade cultural e epistêmica - estão a interdisciplinaridade, a pedagogia intercultural, a luta antirracista e a inclusão dos saberes indígenas, afrodescendentes e de outros povos tradicionais como parte do cânone de saberes válidos" (CARVALHO; ÁGUAS, 2015).

Portanto, desde uma perspectiva macro, iniciativas como esta - que se soma a outras - entra na contramão de um gigantesco processo de descredibilização, subalternização e racismo que, por sua vez, também sempre esteve vinculado a processos de invasão e expropriação. E, se este é o quadro mais amplo de uma trajetória histórica e social, é interessante conciliá-la com uma análise micro, no sentido de observar caminhos capazes 
de fazer frente aos mesmos gigantes dentro da sutileza das relações, no cotidiano da sala de aula, no incerto espaço de convivência entre diferenças a que venho denominando como fronteiriço.

\section{REFERÊNCIAS}

ÁGUAS, Carla. A tripla face da fronteira: reflexões sobre o dinamismo das relações fronteiriças a partir de três modelos de análise. Forum Sociológico, n. 23, p. 1-12, 2013.

Festa e fronteira: as celebrações intersticiais do quilombo de Conceição das Crioulas.

Revista de História das Ideias, v. 35, 2ª Série, p. 463-478, 2017.

ALBARET-SCHULZ, Cristiane; BEYER, Antoine; PERMAY, Jean-Luc; REITEL, Bernard; SELIMANOVSKI, Catherine; SOHN, Christophe; ZANDER, Patricia. La frontière, un object spatial en mutation, 2004. Disponível em: http://espacestemps.revues.org/document842.html, acedido em 28/07/2009.

BHABHA, Homi. The Location of Culture. 1 ed. London and New York: Routledge, 1994.

CARVALHO, José J.; ÁGUAS, Carla. Encontro de Saberes: um desafio teórico, político e epistemológico. Actas do Colóquio Internacional Epistemologias do Sul: aprendizagens globais Sul-Sul, Sul Norte e Norte-Sul. Coimbra, v. 1, p. 1017-1027, 2015.

CARVALHO, José J.; FLÓREZ, Juliana F. Encuentro de Saberes: proyecto para decolonizar el conocimiento universitário eurocêntrico. Nómadas, n. 41, p. 131-147, 2014.

DEMAMANN, Sandra. Educação Ambiental e representações sociais na educação de surdos [Dissertação de mestrado]. Santa Maria, Pós-graduação em Educação, UFSM, 2006.

HALL, Stuart. Who needs 'Identity'?. In: HALL, Stuart; DU GAY, Paul (orgs.). Questions of Cultural Identity. New Delhi: Sage Publications, 1996. p. 1-17.

HANNERZ, Ulf. Fluxos, fronteiras, híbridos: palavras-chave da antropologia transnacional. Mana, v.3, ก. 1, p. 7-39, 1997.

HARTMANN, Luciana; CARVALHO, José J.; SILVA, Renata; ABREU, Joana. Tradição e tradução de saberes performáticos nas universidades brasileiras. Repertório, v. 22, n. 33, p. 8-30, 2019.

INSTITUTO DE INCLUSÃO NO ENSINO SUPERIOR E NA PESQUISA - INCTI. Encontro de saberes: bases para um diálogo interepistêmico. Brasília: INCTI, 2015.

MARTINS, Rui. 0 paradoxo da demarcação emancipatória: a fronteira da época da sua reprodutibilidade icónica. Revista Crítica das Ciências Sociais, n. 59, p. 37-63, 2001.

NEWMAN, David. Border and Bordering: towards an interdisciplinary dialogue. European Journal of Social Theory, v.9, n.2, p. 171-186, 2006.

RIBEIRO, António S. A retórica dos limites. Notas sobre o conceito de fronteira. In: SANTOS, Boaventura (org.). Globalização: fatalidade ou utopia?. Porto: Afrontamento, 2001. p. 463-488. 
A tradução como metáfora da contemporaneidade. Pós-colonialismo, fronteiras e identidades. In: MACEDO, Ana; KEATING, Maria (orgs.). Colóquio de Outono: Estudos de tradução. Estudos Pós-Coloniais. Braga: Universidade do Minho, 2005. p. 77-87.

SANTOS, Antônio B. Colonização, quilombos: modos e significações. 1 ed. Brasília: INCTI, 2015.

SANTOS, Boaventura S. Modernidade, identidade e cultura de fronteira. Tempo Social, n. 5, p. 31-52, 1993.

A crítica da razão indolente. Contra o desperdício da experiência. 3 ed. Porto:

Afrontamento, 2002.

SHIELDS, Rob. Boundary-thinking in theories of the present: the virtually or reflexive modernization. European Journal of Social Theory, v.9, n.2, p. 223-237, 2006.

SILVA, Augusto S. Tempos cruzados: um estudo interpretativo da cultura popular. 1 ed. Porto: Afrontamento, 1994.

WALTER, Roland. Transferências interculturais: notas sobre trans-cultura, multi-cultura, diásporas, 2006. Sociopoética. Disponível em: http://whttp://www.uepb.edu.br/eduep/ sociopoetica/publicacoes/v1n1/v1n1 artigo05.html, acesso em: 26/05/2011.

WOODWARD, Kathryn (2011). Identidade e diferença: uma introdução teórica e conceitual. In: SILVA, Tomaz (org.). Identidade e diferença: a perspectiva dos Estudos Culturais. Petrópolis: Vozes, 2011. p. 772. 